\title{
An Innovative Network Engineering Professional Practice Teaching System Construction and Implementation
}

\author{
Ning Duobiao ${ }^{1, a^{*}}$, Zhao $\mathrm{He}^{1, \mathrm{~b}}$ \\ ${ }^{1}$ Department of Computer Science and Technology of Chengdu Neusoft University, Chendu, \\ Sichuan,China \\ aningduobiao@nsu.edu.cn, ${ }^{b}$ zhaohe@nsu.edu.cn \\ ${ }^{*}$ Corresponding Author
}

\begin{abstract}
This paper analyzes the network engineering professional competence factors and the characteristics of the CDIO engineering education, designs innovative professional practice teaching system based on TOPCARES - CDIO.The composition covers practice teaching conception, practice teaching design, practice teaching implementation etc. The main contents of the system are discussed in detail.
\end{abstract}

Keywords: Network Engineering Specialty, TOPCARES-CDIO.

\section{创新型网络工程专业实践教学体系的构建与实施}

\author{
宁多虎 ${ }^{1, a^{*}}$, 赵荷 ${ }^{1, b}$ \\ 1成都东软学院计算机科学技术系,成都, 四川, 中国 \\ aningduobiao@nsu.edu.cn, bzhaohe@nsu.edu.cn \\ *通讯作者
}

中文摘要. 本文分析了网络工程专业能力 要素和CDIO工程教育的特点, 提出了基于 TOPCARES-CDIO的创新专业实践教学体 系, 并对构成该体系的实践教学构思、实践 教学设计、实践教学实施等核心内容进行了 详细论述。

关键词: 网络工程专业; TOPCARES-CDIO

\section{1. 引言}

近年来, 随着世界各国工程教育改革的 不断深入, 在世界范围内, 高等工程教育的 课程体系和教学内容发生了很大的变化。中
国的高等工科院校在这方面也做了大量工 作, 取得了一些成绩，但从总体上看，我们 的工程教育, 尤其在飞速发展的IT领域, 仍 存在一些阻碍高等工程教育改革和发展的 根本问题:

培养目标和学习效果: 不清晰, 未经 利益相关者认定;

课程体系：相对于市场的技术发展， 企业的实际应用，当前绝大多数高校 讲述的IT专业技术知识, 滞后现象严 重;

、教与学: 教——高校教师普遍缺乏实 际工程经验, 教学偏重于理论; 学一 一因为缺少工程实践场所和完整的工 程实训体系, 学生很难学习到真正完 
整地工程项目经验, 学习到的都是简 单、离散的实训环节的拼接。

\section{CDIO 与TOPCARES-CDIO}

CDIO 工程教育模式是近年来国际工 程教育改革的最新成果。从2000 年起, 麻省 理工学院和瑞典皇家工学院等四所大学组 成的跨国研究获得 Knut and Alice Wallenberg 基金会近2000 万美元巨额资 助, 经过四年的探索研究, 创立了CDIO 工程 教育理念, 并成立了以CDIO 命名的国际合 作组织。CDIO 代表构思(Conceive) 、设计 (Design) 、实现 ( Implement) 和运作 (Operate), 它以产品研发到产品运行的生命 周期为载体, 让学生以主动的、实践的、课 程之间有机联系的方式学习工程。CDIO培 养大纲将工程毕业生的能力分为工程基础 知识、个人能力、人际团队能力和工程系统 能力四个层面, 大纲要求以综合的培养方式 使学生在这四个层面达到预定目标。CDIO 的理念不仅继承和发展了欧美20 多年来工 程教育改革的理念, 更重要的是系统地提出 了具有可操作性的能力培养、全面实施以及 检验测评的 12 条标准。

东软的教育理念：教育创造学生价值. 我们对 CDIO能力培养大纲做了继承基础上 的创新, 调整并增加了部分能力指标, 构建 了具有东软特色的 TOPCARES-CDIO能力 指标体系, 该体系注重引导学生“学会认知, 学会做事, 学会共同生活, 学会生存”。培 养学生自信、自主、自立和合作分享的精神, 作为新世纪的学习者, 培养其成为 “创新的 和实践问题的解决者”、“高效的沟通者”、 “合作的团队成员”、“灵活的、自我指导 的学习者”、“全球意识、积极的、负责任 的公民”, 这既是一个新世纪学习者的基本 素质, 同样也是新世纪工程师的基本素质, 而建立在个人和小组的独立自主、积极主动 探究基础上的探究式教学能够更为充分地 培养这些能力与素质。

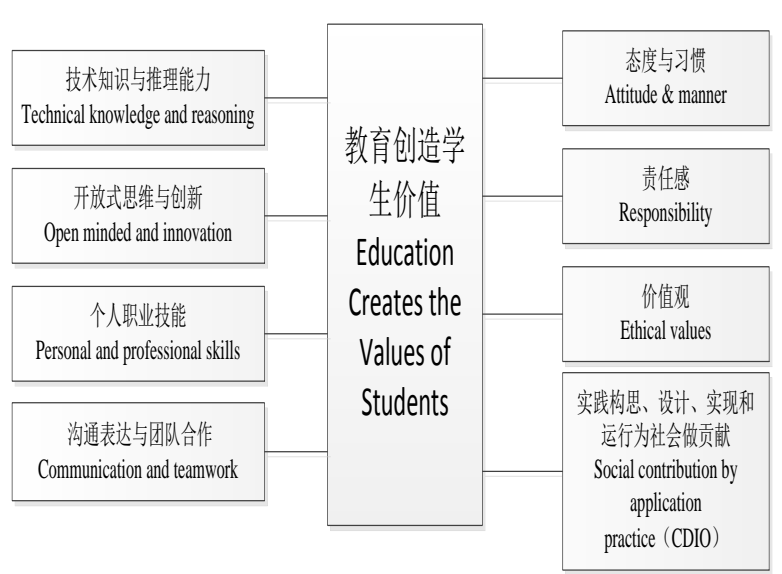

图1 TOPCARES-CDIO能力指标

TOPCARES-CDIO指标体系包含 8 个 一级指标、32 个二级指标和 110 个三级指 标, 采用 “TOPCARES-CDIO 项目教学 法”实施教学。这种教学法是沟通 “TOPCARES” 和 “CDIO”的桥梁, “TOPCARES” 体现了东软学院对学生的 最高关注, “CDIO” 则主张在工程实践中 教育和培养学生。它将学生以继承知识为主 的学习引导至对未知事物主动探索的学习, 较好地解决了学生实践操作能力不足、学科 知识与社会需求脱节严重的矛盾, 并弥补了 传统教学模式中存在的缺口。

\section{3. 网络工程人才能力定位}

网络工程是在计算机科学与技术、通信 等专业或专业方向基础上经过发展逐渐形 成的专业, 随着当今互联网技术的日益普 及, 其专业目标、专业内涵不断丰富, 涵盖 了局域网、广域网、互联网、无线网络与移 动通讯、传感网与物联网以及社交网络等多 个领域。网络工程的研究对象包括网络科学 理论和网络工程技术两个方面。前者的目地 在与理解网络的内在规律和行为特征, 以应 对网络面临的结构复杂、规模庞大以及服务 质量和安全威胁等问题: 而网络工程技术研 究的重点是如何综合运用各种技术和工程 方法设计、构建、维护、管理网络, 并使其 具有扩展性好、可靠性高、安全性强、性价 比搞的特点。在经过充分的调研分析后, 教 育部高等学校计算机科学与技术指导委员 会, 在2012年出版了《高等学校网络工程专 业规范》，在该规范中, 将网络工程专业 能力归纳为: 1 、网络协议分析、设计与实 
现能力; 2、网络设备研发能力; 3 、网络应 用系统设计与开发能力; 4、网络工程规划、 设计与实施能力; 5、网络系统管理与维护 能力; 6、网络系统安全保障能力。这六个 方面的能力相当于六个维度, 每个维度除包 含素质方面的基础知识、能力外, 还有专业 知识和专业能力的培养, 每个毕业生想在6 个维度方面都有较强的专业能力, 也是不现 实的。成都东软学院在充分考虑学生、教师、 产业和社会等利益相关者的需求基础上, 结 合我国高等教育的实际和 IT 行业的人才 需求标准, 定位是为社会培养高质量的 IT 应用型人才。因此, 我院的网络工程专业对 学生专业能力的培养, 重点是第3、4、5、6 项专业能力。

\section{4. 网络工程专业实践教学体系的构建}

东软学院强调知识的运用比知识的拥 有更重要建。教育不仅要向学生传授知识, 更重要的是培养学生运用知识的能力。学院 独具特色的“ 1321 ” 学年设置, 是把 1 个学年3 个学期, 其中 2 个理论学期, 1 个实践学期。 实施基于项目、案例的学习, 强调 “精讲多 练” 的理论教学; 实践学期以项目为载体, 实施基于工程实践的项目实训, 强调 “面向 行业应用的进阶式实践”教学。

\section{1 以构思为先导, 确立网络工程专业实 践教学目标}

网络工程专业实践教学的长远目标是 提升学生的工程素养, 培养学生网络工程实 践能力、工程设计能力和工程创新能力, 培 养支撑互联网行业和产业发展的工程技术 人才; 从近期目标看, 网络工程专业实践教 学的目标是服务于专业课程的学习, 即加深 对网络工程专业各专业课程理论知识的理 解, 并培养初步应用课程知识的工程实践能 力。国内多年的高等工程教育的实践表明, 仅仅依靠离散的课程实践环节, 难以培养学 生的工程实践能力、工程设计能力和工程创 新能力。

为此, 在构思网络工程专业实践教学体 系的过程中, 可借鉴CDIO工程教育的理念, 全面引入大工程观思想, 以实际工程项目为 载体，基于工程项目全方位设计课程实验、
生产实习、科技创新和毕业设计等实践教学 环节, 并综合构思实践教学的实施方式和运 作管理方式, 构建集构思、设计、实施与运 作四位一体的网络工程实践教学体系。

\section{2 以校园网工程为主线, 进行实践教学 体系设计。}

在确立作为重要载体的工程项目时, 我 们通过多方的对比、分析, 最终选取成都东 软学院校园网工程为主线, 遵循“由浅入深、 逐层递进” 的认知规律, 结合东软学院特有 的实训学期教学模式, 设计了网络工程专业 实践教学体系鱼骨图（见图2）。

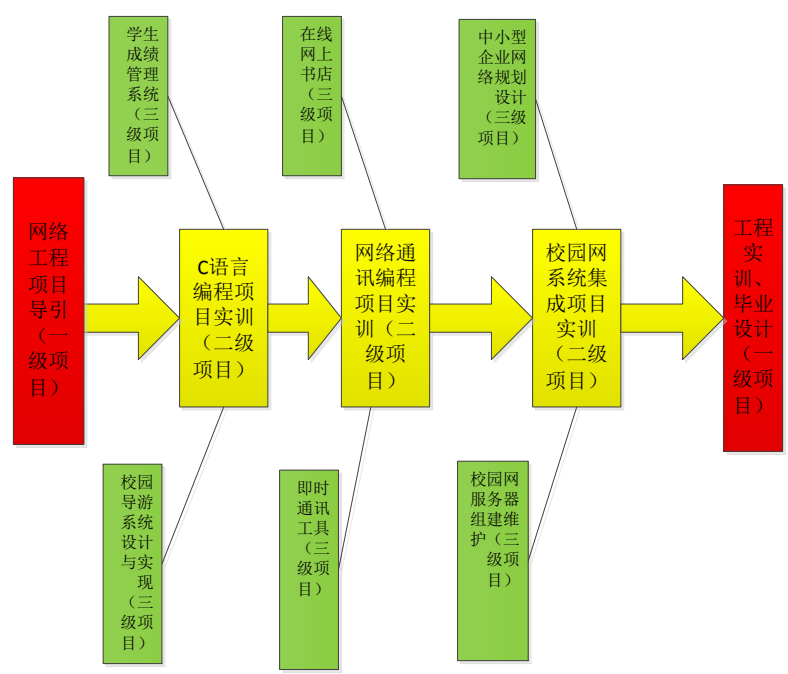

图2 网络工程专业实践教学体系项目鱼骨图

网络工程项目导引开设在新生入学的 第一个学期, 主要以讨论式的教学方式, 让 学生通过多种途径, 广泛收集网络工程专业 在就业市场所针对的就业岗位以及各岗位 所需要的专业技能和素质能力, 让学生熟悉 本专业开设的课程和开设的学期, 同时利用 课外时间参观校园网中心机房、教学楼、宿 舍楼讯井间, 让学生对网络工程整个专业体 系有一个轮廓性的认知。

第一个实训学期安排在大一的第三学 期, 进行的二级项目是: C语言的编程实践 训练, 通过用 C语言编写 “坦克大战” 游 戏, 这样一个趣味性极强的项目, 激发学生 的学习兴趣, 熟悉用 $\mathrm{C}$ 语言完成一个项目, 所需要掌握的逻辑思维能力和编程能力。

第二个实训学期安排在大二的第六学 期, 利用 $\mathrm{C}++$ 语言完成网络通讯, 通过该项 
目的实训, 让学生掌握网络通讯Socket编程 基本技术, 常见开发文档的编写; 在项目的 实训组织上, 按照软件工程项目实际角色分 工, 分组进行, 要求学生掌握软件工程项目 中的角色分工, 掌握项目开发的业务流程, 并通过网络通讯的实施过程, 深入理解所学 习的网络原理等相关课程。

第三个实训学期安排在大三的第九个 学期, 以学生熟悉的本校校园网工程为项目 主线, 从项目的需求分析、IP地址规划、设 备选型、服务器搭建到最后的校园网维护, 让学生从使用 3 年多最熟悉的校园网络入 手, 完成一个完整的网络系统集成工程项 目, 学生4--6人成立一家系统集成公司, 进 行整个工程的招标、投标过程, 熟悉工程项 目的招投标过程。

大四的综合实训和毕业实习作为一级 压顶石项目，学生根据自己的专业特长和职 业发展规划, 可以选择网络应用开发、网络 系统集成、网络运维、网络系统安全等多个 方向的选题, 并与企业实习的真实项目相结 合, 完成从学生到职场工作人员的过渡, 真 正做到毕业就具备直接胜任就业工作岗位 的专业能力和职业素质。充分体现 “TOPCARES-CDIO”工程教育的优势。

\section{3 以学生为中心, 实施开放式实践教学 模式}

传统的实践教学受时间安排、学时数及 实验场所和指导教师等条件的限制, 实践教 学过程中学生的思维活动空间受到了制约, 实践教学的效果无法达到预期的效果,

“TOPCARES-CDIO 学法”, 大胆突破传 统实践教学组织模式的制约, 充分体现以学 生为中心的教育理念, 积极适应学生的发展 要求, 实行开放式实践教学, 为学生提供一 个在时间、空间和实验内容上都有较大选择 性和自由度的实践教学环境, 最大限度地调 动他们参与实践教学的积极性和主动性。

通常的认识性实验可通过视频、查阅资 料或现场参观等方式, 安排在课外时间进 行; 设计性实验和综合性实验需要大量的时 间, 需要采用开放式实践教学组织方式, 学 生可以根据自己的学习情况和实验室的资 源使用情况, 合理安排实验时间, 实验管理 中心组建了专门的学生助理团队, 利用相关
的开放式实验管理系统, 在学生进入实验室 和离开实验室时, 扫描学生证记录学生实验 时间, 记录在对应的实验成绩登记栏, 便于 教师掌握学生的实验完成情况。

学院信息管理中心, 指导学生成立的四 叶草SOVO团队, 协助信息中心教师, 进行 校园网的正常允许维护和故障处理, 学生将 课堂内学习到的理论知识能应用到实际的 校园网维护当中, 极大的激发了学生的学习 兴趣, 他们会主动研究在实际维护过程中碰 到的问题, 探讨当中存在的原理, 并进行经 验的总结。

\section{4 以ABET和过程管理为依托, 建立实践 教学运行的长效质量保证体系。}

教学质量是高等教育的生命线, 对于民 办高校, 保证和提高教学质量是民办高校可 持续发展的前提和保证。

在分析、对比、综合国家相关教育教学 标准, 结合我院教育教学实际发展的基础 上, 将ABET标准与东软本科教育实践相结 合, 做到了 “ABET质量标准横向覆盖, 过 程管理与改善纵向贯穿”, 构建了由相互联 动、自我完善的子系统组成的教学质量运行 保障体系。

实践教学体系建设的核心是培养目标, 利用ABET评价体系建立可文档记录、可测 量的培养目标, 并进行定期评估, 持续改进, 是运行质量保障体系的重要目标。

\section{5. 结束语}

本文就基于 “TOPCARES-CDIO”理 念的网络工程专业的实践教学体系的构建 进行了探讨, 提出的网络工程专业人才培养 方案中项目设计的思路、项目设置架构及项 目实施策略, 为有效培养网络工程应用型人 才提供了一定的参考依据。成都作为全国信 息服务业重要基地, 对网络工程应用型人才 有广泛需求。为了适应西南经济的发展, 作 为培养工程应用型 IT人才的高校, 参考 CDIO 理念重构以项目为载体的实践教学 体系是十分重要和必要的。 


\section{References}

[1] The ministry of education of institutions of higher learning computer science and technology teaching steering committee, Institutions of higher learning network engineering professional norms, Higher Education Press, 7, 2012.

[2] Xu Ming, Cao Jienan, Institutions of higher learning network engineering professional training scheme, Tsinghua University Press, 10,2011.

[3] He Chaoyang, Cao QI, Du Shuwang, On Electronic and Informatiion Engineering Personnel Training Based on C\&P-CDIO Model, Research in Higher Education of Engineering, vol.2,2013.
[4] Dong Faqin, Yan Bin, Dong Xue, To construct the opening practice teaching system Strengthen students' practice ability and innovation ability, China University Teaching, vol.10,2011.

[5] Liu Jingzhi, Li Ning, Hu Jingfan, Zhanghong, Research and practice of the software project comprehensive practice teaching reform based on CDIO model, Computer Engineering \& Science, vol.33,2011

[6] Xu Bin, Study on the Construction of Undergraduate Curriculum System for Innovative Engineering Education, Doctoral Dissertation of Tianjin University , 2010. 